\title{
A Estabilidade constitucional dos celetistas concursados das entidades de direito público
}

A Lei n: 6185, de 11 de dezembro de 1974, sistematizou, no quadro permanente do pessoal civil da União, a dicotomia de regime jurídico: estatutário e contratual:

"Art. 1. - Os servidores públicos civis da Administração Federal direta e autárquica reger-se-ão por disposições estatutárias ou pela legislação trabalhista em vigor".

A distinção fundou-se no caráter da atuação do Estado. Quando ele age no exercício do poder de autoridade ou de funções soberanas (atos de império), os agentes administrativos que cumprem a ação estatal, regem-se, no plano das relações internas de trabalho, pelas normas do ordenamento jurídico (estatuto), ditadas e modificadas, unilateralmente, em lei.

Art. $2^{\circ}$, na redação da Lei 6335 , de 31 de maio de 1976: - "Para as atividades inerentes ao Estado como Poder Público sem correspondência no setor privado, compreendidas nas áreas de Segurança Pública, Diplomacia, Tributação, Arrecadação e Fiscalização de Tributos Federais e contribuições previdenciárias e Ministério Público, bem como para a categoria funcional do Procurador da Fazenda Nacional, só se nomearão servidores cujos deveres, direitos e vantagens sejam os definidos em estatuto próprio, na forma do artigo 109 da Constituição Federal".

Para os demais serviços, que o Estado executa em condições semelhantes aos de um particular, em que as partes se encontram no mesmo nivel jurídico de igualdade (atos de gestão), é o 'contrato' o insti- tuto regulador dos vínculos de trabalho: Art. $3^{\circ}$ Para as atividades não compreendidas no artigo precedente, só se admitirão servidores regidos pela legislação trabalhista, sem os direitos de greve e sindicalização, aplicando-se-Ihes as normas que disciplinam o Fundo de Garantia do Tempo de Serviço".

É, portanto, o contrato nominado ou típico de 'emprego', nos termos em que, fundamentalmente, disciplinado na Consolidação das leis do trabalho, o instrumento jurídico das relações entre o Estado e esses agentes cujas ações não revestem o cunho incontratável da 'autoridade'.

Tal critério, da Lei n. 6185, de 1974, é questionável à luz dos lineamentos básicos da Emenda Constitucional, de 1969. Na Seção VIII, intitulada "Dos Funcionários Públicos", prevê-se uma diferenciação de regime fundada apenas ou na duração das funções ou na sua índole, técnica especializada: "Art. 106 - O regime jurídico dos servidores admitidos em serviços de caráter temporário ou contratado para funções de natureza técnica especializada será estabelecido em lei especial".

A previsão constitucional de 'regime especial' implica o prius lógico de haver um 'regime geral', pela mesma razão de não poder falar-se em exceção sem antes estabelecer a regra excepcionada.

Mas não é apenas por imperativo das leis do raciocínio que se chega à exigência de uma disciplina-padrão para os atores da ação estatal. Éo próprio 'diploma político' que manda definir o regime jurídico comum ou geral: "Art. 109 - Lei federal, de iniciativa exclusiva do Presidente da República, respei- 
tado o disposto no art. 97 e seu $\S 1^{\circ}$ e e no $\S 2^{\circ}$. do art. 108, definirá: 1 . o regime jurídico dos servidores públicos da União, do Distrito Federal e dos Territórios".

É verdade que a doutrina administrativa tende a ver no uso da expressão "servidores públicos" uma indicação para distinguir o tratamento dos agentes entre "funcionários strictu sensu", investidosem "cargos", criados por lei, com denominação própria, em número certo e pagos pelos cofres da União (Estatuto dos funcionários públicos civis da União, Lei n: 1711, de 1952, art. 2.'), e os demais exercentes de funções ou empregos públicos. Verse-á, entretanto, que essa e outras locuções da Carta de 1969 relativas a pessoal são, em linha de principio, empregadas em acepção ampla, não autorizando um discrime sistemático.

A constitucionalização das normas sobre os agentes administrativos integra-se no título maior da "Organização Nacional", no contingente mais numeroso da força de trabalho do Estado, o art. $108 \mathrm{faz}$ certo que as disposições de Seção VIII aplicam-se também aos funcionários do Legislativo e Judiciário da União, e até mesmo, dos Estados, Distrito Federal, Territórios, e Municípios. Procurando identificar os elementos determinantes para uma sistematização de regimes, dois critérios exsurgem dos arts. 106 e 109: a duração dos serviços e a natureza deles.

Á ótica do primeiro, os serviços classificam-se em permanentes ou temporários conforme a previsibilidade legal de sua continuidade. As funções que consubstanciam, perenes ou transitórias, vão plasmar os órgãos e condicionar a posição de seus tripulantes, definindo-Ihes por esse pressuposto existencial o tipo ou regime de trabalho. No balanço dos encargos públicos, é manifesta a prevalência das necessidades a que o Estado é chamado a satisfazer sem limitação de tempo. A massa dos serviços permanentesé, pois, a regra e imprime às relações prestador-órgão o tom genérico ou comum das normas disciplinadoras.

Pelo segundo critério constitucional, toma-se em conta a natureza dos conhecimentos, de instrução básica ou científico-artísticos que o servidor há de possuir a fim de desempenhar as funções correspondentes. Aliás, a Emenda Constitucional de 1969, restringiu, ou por involuntário lapso de redação ou de indústria, o âmbito da disposição. Enquanto o art. 104 da Constituição de 1967 contemplava duas atividades, "técnicas ou especializadas", suscetíveis de disciplinamento próprio nas relações de serviço, a versão atual limitou a permissão apenas aos ofícios técnicos especializados. Não basta, destarte, que a execução do trabalho exija formação profissional reconhecida; é mister ainda que nessa esfera haja diferenciação de setores que requeira habilitação mais específica ou especializada.
É, por conseguinte, a partir das funç̃̃es administrativas do Estado que cumpre ao legislador ordenar segundo os critérios constitucionais - tempo e natureza - para definir a regência jurídica daqueles que as dinamizam: os funcionários. O quadro básico desenha-se, assim:
A) Tempo
funções permanentes;
funçত̃es temporárias.
B) Natureza do funções ordinárias ou de
conhecimento instrução básica;
funções técnicas;
funções técnicas especializadas.

O tempo, por sua vez, é a dimensão mais continental que envolve todos os fatos jurídicos, por diversas que seja sua natureza. Daí porque, integrados os dois critérios e transpondo-os das funções para seus funcionários, obtém-se este resultado:
A) Funcionários de serviços permanentes;
a) de conhecimento ordinário;
b) de conhecimento técnico;
C) de conhecimento técnico especializado;

B) Funcionários de serviços temporários;
a) de conhecimento ordinário;
b) de conhecimento técnico;
c) de conhecimento técnico especializado.

Predomina na doutrina administrativa hodierna, nacional e estrangeira, a concepção estatutária do vínculo do servidor com o Estado. Rematando o exame das teorias unilaterais e contratuais sobre a prestação do trabalho público, conclui Oswaldo Aranha Bandeira de Mello: "adotada a teoria do ato unilateral ou do ato convencional, união ou acordo, na formação do vínculo jurídico entre o Estado e o agente público, a situação jurídica do agente público é sempre estatutária, de caráter objetivo, impessoal, abstrato, por decorrer dos textos constitucionais, legais e regulamentares" (Princípios gerais de direito administrativo. vol. II. edição 1974, p. 356).

Pela prevalência da condição estatutária, manifestam-se, entre outros, Seabra Fagundes (Revista Forense. vol. 88/221), Caio Tácito (Revista de Direito Administrativo. vol. 35/34), Hely Lopes Meirelles (Direito administrativo brasileiro. 8 ed. p. 381), Celso Antônio Bandeira de Mello (Apontamentos sobre os agentes eórgãos públicos. 1 ed. 3. tiragem p. 10$)$.

O imperativo de aperfeiçoar a estrutura dos serviços para ajustar-se e atender às cambiantes e múltiplas necessidades do meio social em que atua, impõe ao Estado um relacionamento flexível com sua força de trabalho pela votação de leis que possam, unilateralmente, criar, suprimir ou modificar 
normas reguladoras das funções públicas. Salvo o núcleo básico de direitos e garantias assegurados na Constituição, e respeitados os efeitos jurídicos produzidos na vigência das disposições incidentes sobre os fatos funcionais, o legislador pode a todo tempo reformular as atribuições, a retribuição, o modo e a duração da prestação dos agentes administrativos com a finalidade de bastar o interesse público. O condicionamento estatutário é, assim, imanente à gestão oficial e constitui o 'regime geral' ou típico de seus servidores.

A lei ordinária não pode desconhecer o modelo institucional para, à guisa de definir os direitos e deveres que compõem esse regime (art. 109, I), optar por concepção antípoda - a contratual - erigindo em regra o que a Constituição só admite em termos de exceção nos casos mencionados no art. 106.

A mútua subordinação das vontades, no ajuste empregatício, constrange a eficácia legislativa do Estado que esbarra na imodificabilidade unilateral das condições estabelecidas na data da constituição do vínculo e nos ônus que o rompimento da situação acarreta. Mesmo nos chamados contratos de direito público, em que se reconhece ao estipulante oficial maior liberdade na alteração do conteúdo regulamentar, ficando, assim, a meio caminho entre o ato convencional privado e o estatuto, subsistem cláusulas mínimas, irredutiveis à inovação do Estado sem as devidas compensações econômicas. Por outro lado, se o critério jurídico que distingue o poder de autoridade, do poder da gestão não é estanque, porque ao órgão e ao próprio servidor incumbe, a mais das vezes, realizar atos de ambas as naturezas; nem diversifica, substancialmente, o grau de cumprimento dos deveres - avulta, contudo, em termos de organização do trabalho, sancionando discriminações que comprometem a coesão funcional. A duplicidade de regimes submete a tratamento díspar pessoas que militam no mesmo lugar de atividades, sob hierarquia comum, e concorrem nos limites de suas habilitações para os serviços permanentes do órgão. Quebra-se a uniformidade da administração de pessoal que deve ter seus operadores afeiçoados a princípios e normas heterogêneos para o genciamento estatutário e celetista. Enfim, tudo conspira, no plano teórico e prático, para banir-se a dicotomia da Lei n. 6185/74 e voltar à pureza do critério constitucional.

Atento à classificação básica das funções pelo tempo e natureza do conhecimento, e sendo o estatuto a regra das relações entre o Estado e seus agentes, define-se o alcance de cada regime nestes termos:

\section{A) Estatuto}

a) Geral: necessidade permanente de serviços

- ordinários

- técnicos

- técnicos especializados.

b) Especial: necessidade temporária de serviços

- ordinários

- técnicos

- técnicos especializados.

B) Contrato-especial: necessidade temporária de serviços.

- ordinários

- técnicos

- técnicos especializados.

Vê-se, assim, que a diferenciação de sistemas só pode ocorrer em relação às necessidades temporárias. Estas podem advir ou da inexistência de funções próprias no quadro permanente, sobretudo em decorrência de surgimento de novas técnicas e de outros horizontes de trabalho ou, embora contempladas, seu número não possa atender a um surto extraordinário de demanda. De qualquer sorte, a nota característica é a precariedade até a cessação dos encargos especiais, a normalização do ritmo de trabalho ou incorporação das novas solicitações pela criação ou aumento das respectivas funções permanentes. O legislador federal pode, valendo-se do art. 106 da Constituição, adotar estas soluções para a hipótese:

A) Ou um estatuto especial a exemplo do que, no passado, fez com os extranumerários (Lei n? 1711, de 1952, art. 252, II), que, na concepção original, não podiam estabilizar-se em razão do caráter contingente dos serviços a que eram admitidos, mas acabaram revelando-se permanentes com sua duração ao longo de anos que veio afinal justificar a disposição constitucional transitória de 1946 e as sucessivas leis que outorgaram efetividade ou estabilidade aos exercentes;

B) Ou optar pelo regime especial de contrato, de direito público ou privado. A contratação pode revestir variada forma em função das conveniências ou do tipo de prestação, autônomo ou subordinado, por convenções nominadas (locação de serviços, empreitada de lavor, contrato de emprego) ou inominadas de acordo com o grau de discrição conferido pela lei à gestão oficial. O contrato é, por vocação, o instrumento mais ajustado à regulamentação das necessidades temporárias de serviço, porque gera relações de fundo marcadamente transeunte. $\mathrm{O}$ art. 106 da Emenda de 1969 elege-o, da maneira expressa, quando alude a "contratados para funções de natureza técnica especializada".

Essa visão da problemática do pessoal insere- 
se de certo modo no entendimento que Adilson Abreu Dallari perfilha em seu Regime constitucional dos servidores públicos (edição de 1976, p. 105). A Constituição de 1967 (art. 104), que sujeitava, rigidamente, 0 acudimento das necessidades provisórias à bitola única do contrato de emprego, evoluiu na Carta de 1969 (art. 106) para um tratamento mais dúctil, abrindo ao legislador federal a escolha dos regimes e a modelação de direitos e deveres dentro dos mínimos constitucionais assegurados a todos os trabalhadores.

Por ser o arcabouço da organização do Estado brasileiro e dos direitos e garantias individuais, a norma constitucional estabelece linhas básicas cujo desdobramento há de definir-se em função de sua própria sistemática e dos princípios que consagra. As formulações da legislação ordinária cumprem entender-se como um estágio do processo de revelação constitucional sem exaurir as potencialidades do texto fundamental. Dentro desse alcance, devem ser recebidas as menções do constituinte a "funcionários", "servidores" e "cargos". No lugar específico em que a matéria é versada (Seção VIII do Capítulo VIII, o título "Dos Funcionários Públicos" já denuncia o emprego geral da expressão para cobrir os quinze artigos elevados à hierarquia mais alta das normas jurídicas. Tomando-se por amostragem algumas dessas disposições e cotejando o uso dos mesmos termos, confirma-se o sentido amplo em que, de regra, são aplicados. Assim, quando, no art. 99, excetua-se da acumulação remunerada de cargos e funções públicos - e o caráter excepcional obriga a um entendimento mais estrito - "II - a de dois cargos de professor" ou "IV - a de dois cargos privativos de médico", a dicção 'cargo' exprime, simplesmente, uma unidade funcional qualquer que seja o regime, estatutário ou contratual. No mesmo diapasão, cumpre acolher-se a solene afirmativa do art. 97: "Os cargos serão acessiveis a todos brasileiros que preencham os requisitos estabelecidos em lei". Não há tergiversar que por aí se asseguram ao geral dos nacionais as funções públicas sem discriminação de disciplina jurídica. Em relação aos "funcionários", sobre ser irrestrito o alcance que dá nome à própria seção, o art. 107 corrobora que o apelativo abrange toda gama de agentes administrativos ao tornar as pessoas de direito público responsáveis pelos danos a terceiros, sejam os causadores estatutários ou celetistas. Finalmente, no tocante aos "servidores" em que a doutrina tende a compendiar a coletividade dos trabalhadores estatais, o designativo aparece em correspondência perfeita a "funcionários". Consulte-se o art. 108 para ver que o caput, depois de mandar aplicar o disposto na seção aos "funcionários" dos três Poderes da União, Estados, Distrito Federal, Territóriose Municípios, especifica, no parágrafo segundo, que os Legislativos e Judi- ciários "somente poderão admitir servidores mediante concurso público de provas, ou provas e títulos após a criação dos cargos respectivos..." Em uma única assentada, exemplifica-se o emprego equivalente e correlativo de "funcionários", "servidores" $e^{\text {"cargos". }}$ Mas se a correspondência é a regra, cabe, porém, notar que a Lei Maior, quando pretende singularizar o sentido desses termos, ou contrasta-os na enumeração como ilustra o art. 57 (Competência exclusiva do Presidente da República para a iniciativa das leis que: "II - criem cargos, funções ou empregos públicos....)"; ou determina seu alcance mediante acréscimo de complemento a exemplo do art. 104, na redação da Emenda . $^{\circ} 6$ :"o servidor público federal, estadual ou municipal, da administração direta ou indireta, exercerá o mandato eletivo, obedecendo as disposições deste artigo", a compreender, inclusive o pessoal das entidades com personalidade de direito privado (art. 170, $\$ 2^{\circ}$ ) integrantes da Administração Indireta.

Esse demonstrativo autoriza a concluir que a terminologia funcional da Constituição é genérica e as normas sobre os "funcionários públicos" aplicam-se, em linha de princípio, a todos os agentes administrativos. Sendo assim, a interpretação articulada dos textos identifica as fontes dos regimes jurídicos de pessoal: no art. 109, o geral das funções permanentes do Estado, que é o estatutário; no art. 106, o especial para as funções temporárias: contratual ou estatutária. A Lei n. 6185, de 1974, desviouse da vertente constitucional, ao desprezar os critérios básicos de tempo e saber das funções para estabelecer - uma diferenciação pelo poder jurídico que Ihes seja atribuído.

Ao preceituar de forma imperativa que lei federal, de iniciativa do Presidente da República, "definirá: I - o regime jurídico dos servidores públicos da União, do Distrito Federal e dos Territórios" (art. 109), objetiva-se ordenar, de forma própria, os vínculos entre essas pessoas de direito público e seus braços. Compendiará, necessariamente, as condicões constitucionais da relação funcional, desde a instituição, o desenvolvimento até a extinção, bem como os direitos e deveres recíprocos, e as prescriçত̃es complementares. Qualquer que seja a disciplina que o legislador ordinário adote para as funçত̋es permanentes, não poderá esquivar-se às balizas constitucionais: a inicial, o concurso público de provas para a primeira admissão salvo as exceçðes dos parágrafos $1^{\circ} \mathrm{e} 2^{\circ}$. do art. 97; a intermédia, a estabilidade após o biênio de exercício (art. 100); a terminal, a prévia e ampla defesa para a demissão do estável (art. 105; II).

Mesmo se se admitisse a compatibilização do regime empregatício privado com o estatuto das funções públicas permanentes, não poderia a Lein? 
6185 , como faz no art. $3^{\circ}$, aplicar a legislação trabaIhista e o Fundo de Garantia do Tempo de Serviço sem conformar suas prescrições, naquilo que se interferirem, com os esquemas institucionais próprios. Verbi gratia, não pode ser recusada ou convertida em pecúnia a estabilidade constitucional, a qualquer agente que integra a força permanente de trabalho da pessoa de direito público, seja qual for sua atribuição, de império ou gestão, quando tiver sido provido mediante concurso público de provas. Trata-se de garantia de ordem pública, irrenunciável e intransigivel que, protegendo o vínculo laboral preserva também o exercício dos deveres legais inerentes à função pública.

À mesma conclusão, embora por outros caminhos, chegar-se-ia à luz do art. 109 da Carta de 1969 se se perseverasse na visão literal de que o emprego da locução "servidor público" exprimiria um gênero de trabalhadores, capaz de autorizar distinção por espécie para fim de tratamento jurídico: os estatutários ou funcionários strictu sensu; e os celetistas ou empregados públicos. A determinação que à lei federal cumprirá definir "III - as condições para aquisição de estabilidade", e a destinação ampla - des- se dispositivo, (art. 109, I), aos "servidores públicos" - não abre margem ao legislador ordinário para excluir dessa outorga qualquer espécie de agente, de funções permanentes. Somente em relação ao tempo de aquisição poderia admitir-se que a lei estabelecesse prazo maior de dois anos. Ou para os "funcionários strictu sensu" não concursados, nos casos em que vier a implementar-se a exceção aberta no art. 97, § $1^{\circ}$. da Constituição; ou para os demais tipos de funcionários permanentes, inclusive os celetistas. Nesses termos, faria sentido a aplicação da estabilidade decenal, da Consolidação das leis do trabalho (art. 492). Jamais, porém, a imperatividade do art. 109, III do vigente Estatuto Político toleraria a opção legislativa pelo Fundo de Garantia . do Tempo de Servico como alternativa ao regime de estabilidade (art. 165, XIII) para os servidores das pessoas de direito público em funções permanentes.

Nota

1. Celetista: neologismo forense, formado da sigla C.L.T., designativo dos servidores regidos pela Consolidação das leis do trabalho.

37 